\title{
Synthesis of 2 - ((4-Substituted Phenyl) Amino) Benzaldehyde
}

\author{
Yongli Duan, Zhimin $\mathrm{Li}^{\mathrm{a}}$, Qidong Tang, Rui Li and Shan Xu
}

School of Pharmacy, Jiangxi Science \& Technology Normal University, Nan chang 330013, China

\author{
a110197421@qq.com, bshanxu9891@126.com
}

Keywords: 2-((4-substituted phenyl) amino) benzaldehyde; Synthesis; Process optimization

\begin{abstract}
. 2-((4-substituted phenyl) amino) benzaldehyde, is an important intermediate for the synthesis of many biologically active intermediates of anticancer drugs. In this work, a rapid and high efficiency synthetic method for compound 1a-1b was established. Compound 1a-1b was synthesized from 2-chloronicotinic acid and 4-substituted anilines through three steps including nucleophilic substitution, reduction and oxidation reaction. The structure of the target compound $1 \mathrm{a}-1 \mathrm{~b}$ was confirmed by H NMR and MS spectrum. Furthermore, the synthetic method was optimized. The total yield of the three steps was $59.49 \%$.
\end{abstract}

\section{Introduction}

Cancer is a serious disease that threatens human health and life.There were 14.1 million new cancer cases, 8.2 million deaths and 32.6 million people living with cancer (within 5 years of diagnosis) in 2016 worldwide[1-3]. also known as malignant tumor, is caused by the disorder of cell proliferation mechanism, which usually results from the abnormal activation of some enzymes cancer also has been the second $b$.iggest killer of human beings, taking the lives of over 7 million people a year[4-6] Although a range of antitumor drugs have been discovered in the last decade, drug resistance and adverse side effects are still serious problems. therefore, it remains desirable to develop new antitumor agents with improved tumor selectivity, efficiency, and safety.

In recent years, there were many small molecule anticancer drugs had been reported. Among them, many molecules contained the 2-((4-substituted phenyl)amino)benzaldehyde (1). Therefore, design and synthesis of 2-((4-substituted phenyl)amino)benzaldehyde (1) derivative as small molecule inhibitors played a great role in the study of anticancer drugs. The structures of these compounds were shown in Fig.1. For example, 3-(5-(1H-imidazol-1-yl)-1H-benzo[d]imidazol-2-yl)-N-phenylpyridin-2-amine(2)[7],

3-oxocyclohex-1-en-1-yl 2-oxo-1-phenyl-1,2-dihydro-1,8-naphthyridine-3-carboxylate(3)[8], (E)-3-((1H-indol-6-yl)amino)-1-(2-(phenylamino)pyridin-3-yl)prop-2-en-1-one(4)[9],

(E)-N-phenyl-3-(3,4,5-trimethoxystyryl)pyridin-2-amine(5)[10].

The synthesis of most 2-((4-chlorophenyl) amino) benzaldehydes is reported. In the literature, there are shortcomings in the synthesis route, including esterification reaction, substitution reaction and reduction reaction.[11-12] The product and reaction temperature are high and the by-products are harmful to the environment. 2-((4-chlorophenyl) amino) benzaldehyde is a key intermediate for anti - breast cancer, lymphoma and colon cancer[13-14]. Therefore, the optimization of synthetic routes and methods. 2-((4-chlorophenyl) amino) benzaldehyde. In this study, we designed and optimized the synthesis of 2-((4-chlorophenyl) amino) benzaldehyde, making it more suitable for industrial production. by optimizing the reaction temperature is significantly reduced, less time-consuming, it is important to significantly improve production. 


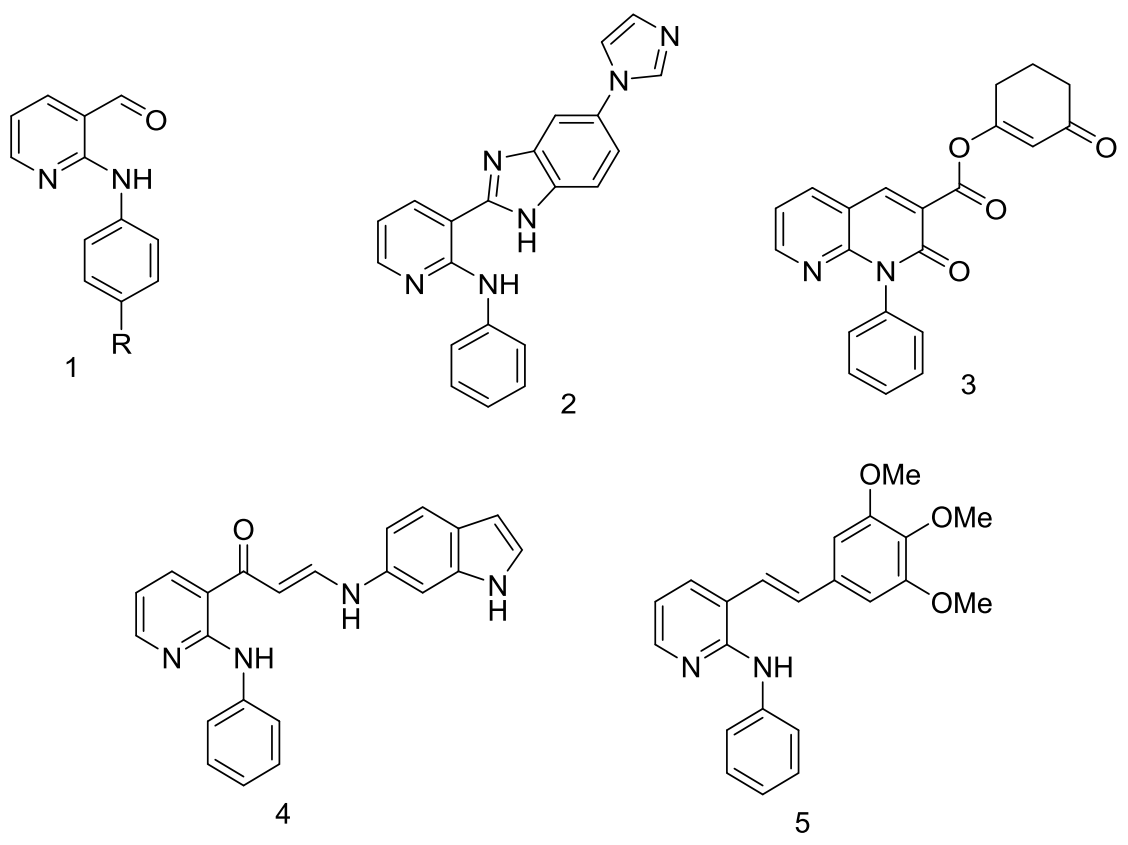

Figure 1. Intermediates and intermediates containing the active compound

\section{Materials and Methods}

NMR spectra were performed using Bruker $400 \mathrm{MHz}$ spectrometers (Bruker Bioscience, Billerica, MA, USA) with TMS as an internal standard. Mass spectra (MS) were taken in ESI mode on Agilent 1100 LC-MS (Agilent, Palo Alto, CA, USA). All the materials were obtained from commercial suppliers and used without purification, unless otherwise specified. Yields were not optimized. TLC analysis was carried out on silica gel plates GF254 (Qindao Haiyang Chemical, China).

\section{Synthesis of Compounds}

The structures and the synthetic route were shown in Scheme 1.

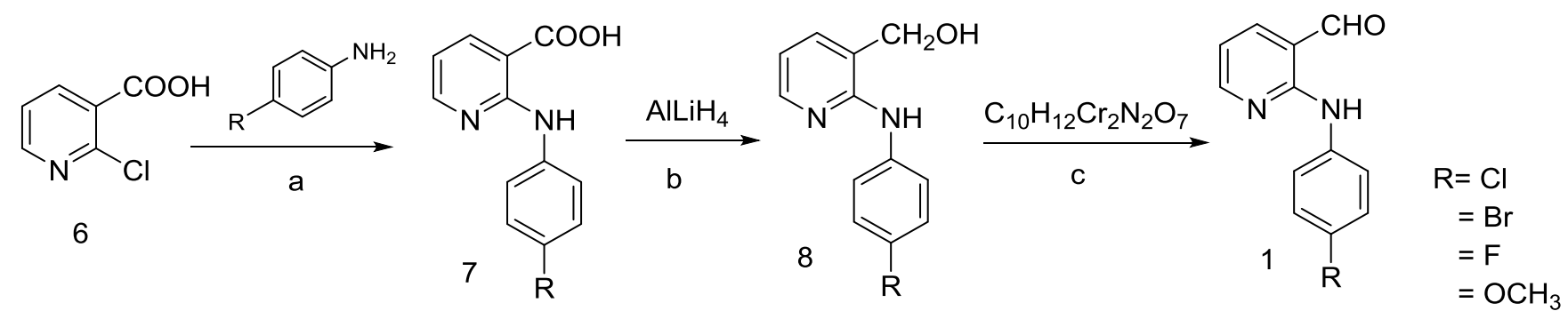

Scheme 1. The synthetic route of compounds $1 \mathrm{a}-1 \mathrm{~b}$

Reagents and Conditions:(a)acetic acid, $100{ }^{\circ} \mathrm{C}$ reflux, $5 \mathrm{~h}$; (b)THF $\mathrm{N}_{2}$ protection r.t $4.5 \mathrm{~h}$; (c) $\mathrm{CH}_{2} \mathrm{Cl}_{2}$. Pyridinium dichromate salt, r.t $6 \mathrm{~h}$.

\section{2-(Phenylamino)nicotinic acid (7a-7b)}

To the mixture of 4-substituted anilines $(5.9 \mathrm{~g}, 0.175 \mathrm{~mol})$ and 2-chloronicotinic acid $(5.0 \mathrm{~g}$, $0.167 \mathrm{~mol})$, in acetic acid $(75 \mathrm{~mL})$. After stirring for $2 \mathrm{~h}$ at $100{ }^{\circ} \mathrm{C}$, the reaction was complete by TLC analysis. The mixture was transferred to a beaker, dilute water was added slowly with stirring maintaining the temperature below $20{ }^{\circ} \mathrm{C}$, the final $\mathrm{pH}$ was 9-10. Filtration, take filtrate, then adjusted the $\mathrm{pH}$ to 6-7 with Hydrochloric acid, under ice bath, filtration, the filter cake was washed with ice-water, dried to obtain a white solid (75-85\%). 
2-((4-Chlorophenyl)Amino)Benzoic Acid (7a). Yellow solid. Yield 77\%. ${ }^{1} \mathrm{H}$ NMR (400 MHz, DMSO) $\delta 10.83(\mathrm{~s}, 1 \mathrm{H}), 8.39-8.34(\mathrm{~m}, 1 \mathrm{H}), 8.25(\mathrm{dd}, J=7.7, \mathrm{~Hz}, 1 \mathrm{H}), 7.77(\mathrm{~d}, J=8.8 \mathrm{~Hz}, 2 \mathrm{H})$, $7.35(\mathrm{~d}, J=8.8 \mathrm{~Hz}, 2 \mathrm{H}), 6.88(\mathrm{dd}, J=7.7,4.8 \mathrm{~Hz}, 1 \mathrm{H}) . \mathrm{ESI}-\mathrm{MS} \mathrm{m} / \mathrm{z}:[\mathrm{M}+\mathrm{H}]^{+} 248.1$.

2-((4-Bromophenyl)Amino)Benzoic Acid(7b). Yellow solid. Yield 85\%. MS (ESI): m/z [M+H] +292.9 .

(2 - ((4-Substituted Phenyl) Amino) Pyridin-3-Yl) Methanol(8a-8b). The THF(40 mL)was transferred to a beaker, dilute Tetrahydroaluminium $(1.64 \mathrm{~g}, 0.357 \mathrm{~mol})$ was added slowly with stirring maintaining $15 \mathrm{~min}$, the temperature below $0{ }^{\circ} \mathrm{C}$, A solution of 2-(phenylamino)nicotinic acid $(3.8 \mathrm{~g}, 0.185 \mathrm{~mol})$ in THF $(40 \mathrm{~mL})$, then it was added drop-wise to a suspension of Tetrahydroaluminium in THF solution at room temperature, control the drip rate and the temperature was kept blow $0{ }^{\circ} \mathrm{C}$ keep the reaction for $6.5 \mathrm{~h}$, , the reaction was complete by TLC analysis. The mixture was transferred to a beaker, dilute Ethyl acetate was added slowly with stirring, Filtration, the filtrate was concentrated under reduced pressure to afford product as a yellow viscous oil (60-88.\%) and was used for next step without further purification.

(2-((4-Chlorophenyl) Amino) Phenyl) Methanol (8a). Orange solid. Yield 70\%. ESI -MS m/z: $[\mathrm{M}+\mathrm{H}]^{+} 234.7$.

(2-((4-Bromophenyl) Amino) Phenyl) Methanol (8b). Orange solid. Yield 73\%ESI -MS m/z: $[\mathrm{M}+\mathrm{H}]^{+} 280.1$.

2-((4-Substituted Phenyl)) Amino) Nicotinaldehyde(1a-1b). A solution of Pyridinium dichromat salt and (2-((4-substituted phenyl))amino)pyridin-3-yl)methanol (5.28 g,0.258 mol) was stirred at room temperature for $7 \mathrm{~h}$. Filtration, the filtrate was concentrated under reduced pressure to afford product as viscous oil, The mixture was cooled $2 \mathrm{~h}$ to afford the target compound as pale yellow solid(,65-89.4\%)

2-((4-Chlorophenyl) Amino) Nicotinaldehyde (1a). Yellow solid. Yield $78{ }^{1} \mathrm{H}$ NMR (400 MHz, DMSO) $\delta 10.35(\mathrm{~s}, 1 \mathrm{H}), 9.86(\mathrm{~s}, 1 \mathrm{H}), 8.37(\mathrm{~d}, J=2.2 \mathrm{~Hz}, 1 \mathrm{H}), 7.85(\mathrm{dd}, J=5.2,2.2 \mathrm{~Hz}, 1 \mathrm{H})$, 7.64-7.70(m, 2H), 7.00-7.09 (m, 2H), 6.83 (dd, $J=4.5,3.0 \mathrm{~Hz}, 1 \mathrm{H})$; ESI-MS m/z: $[\mathrm{M}+\mathrm{H}]^{+} 232.4$.

2-((4-Bromophenyl) Amino) Nicotinaldehyde (1b). Yellow solid. Yield $73 \%{ }^{1} \mathrm{H}$ NMR (400 MHz, DMSO) $\delta 10.41(\mathrm{~s}, 1 \mathrm{H}), 9.96(\mathrm{~s}, 1 \mathrm{H}), 8.50(\mathrm{~s}, 2 \mathrm{H}), 8.23(\mathrm{~s}, 1 \mathrm{H}), 7.76(\mathrm{~s}, 3 \mathrm{H}), 7.05(\mathrm{~s}$, 1H).ESI -MS m/z: $[\mathrm{M}+\mathrm{H}]^{+} 278.9$.

\section{Conclusions}

In general, the synthesis of 2 ((4-substituted phenyl)) amino) nicotinamide (1) from 2(phenylamino) nicotinic acid was optimized by three steps including nucleophilic substitution, reduction and oxidation. Optimization by synthesis method, the reaction time is shortened, the temperature is relatively mild, the byproduct is less, and the yield of the target compound 8 is higher. Its structure was confirmed by $1 \mathrm{H}$ NMR.

\section{Acknowledgments}

We gratefully acknowledge the generous support provided by The National Natural Science Funds of Jiangxi Science \& Technology Normal University (2016XJZD007) and College Students' Science and Technology Innovation Project of Jiangxi Province and Graduate Students' Innovation Project of Jiangxi Science \& Technology Normal University.

\section{References}

[1] Kumar Mahto M, Yellapu N K, Kilaru R B, et al. Molecular designing and in silico evaluation of darunavir derivatives as anticancer agents[J]. Bioinformation, 2014, 10(4): 221.

[2] Dayyani F, Gallick G E, Logothetis C J, et al. Novel therapies for metastatic castrate-resistant prostate cancer [J]. Journal of the National Cancer Institute, 2011, 103(22): 1665-1675. 
[3] Barth H, Bridges A, Heemstra R, et al. Preparation of substituted quinazolines: U.S. Patent Application 10/771,774[P]. 2004-2-4.

[4] Zhang D. Bicyclic compounds as kinases inhibitors: U.S. Patent Application 14/401,108[P]. 2013-5-13.

[5] Zhang J, Zhang Y, Zhang W, et al. Aminoquinazoline derivatives and their salts and methods of use: U.S. Patent Application 14/346,741[P]. 2012-11-14.

[6] Lee K, Kim J, Jeong K W, et al. Structure-based virtual screening of Src kinase inhibitors [J]. Bioorganic \& medicinal chemistry, 2009, 17(8): 3152-3161.

[7] Guengoer T, Fouquet A, Teulon J M, et al. ChemInform Abstract: Cardiotonic Agents. Synthesis and Cardiovascular Properties of Novel 2- Arylbenzimidazoles and Azabenzimidazoles.[J]. ChemInform, 1993, 35(21):4455-63

[8] Takabe F, Hirano Y, Funyu A, et al. Ring-fused 2-pyridone derivatives and herbicides: EP, US8334236 [P]. 2012.

[9] Kamal A, Reddy V S, Vishnuvardhan M V P S, et al. Synthesis of 2-anilinopyridine-arylpropenone conjugates as tubulin inhibitors and apoptotic inducers [J]. Rsc Advances, 2015, 5(118):97367-97380.

[10] Kamal A, Ashraf M, Basha S T, et al. Design, synthesis and antiproliferative activity of the new conjugates of E7010 and resveratrol as tubulin polymerization inhibitors.[J]. Organic \& Biomolecular Chemistry, 2016, 14(4):1382-1394

[11] Ham Y J, Gong J H, Cha M Y, et al. Quinazoline derivatives for inhibiting cancer cell growth and method for the preparation thereof: U.S. Patent 8,003,658[P]. 2011-8-23.

[12] Bae I H, Byun E Y, Ju H K, et al. Quinoline or quinazoline derivatives with apoptosis inducing activity on cells: U.S. Patent 8,835,458[P]. 2014-9-16having an inhibitory effect on signal transduction mediated by tyrosine kinases: U.S. Patent 6,972,288[P]. 2005-12-6

[13] Having an inhibitory effect on signal transduction mediated by tyrosine kinases: U.S. Patent 6,972,288[P]. 2005-12-6Ahn Y G, Kim J W, Bang K C, et al.

[14] Quinazoline derivatives as a multiplex inhibitor and method for the preparation thereof: U.S. Patent 8,846,699[P]. 2014-9-30. 